\title{
A falseabilidade de Popper nas pesquisas em contabilidade no Brasil de 2009-2014
}

The Popper falsifiability in accounting research in Brazil from 2009 to 2014

La falsabilidad de Popper en las investigaciones en contabilidad en brasil de 2009 a 2014

\section{Iara Vigo de Lima}

Pós-doutora na Fundação Adam Smith, Universidade de Glasgow, Escócia - Reino Unido Professora do Departamento de Economia e da Pós-Graduação em Políticas Públicas na Universidade Federal do Paraná - UFPR

Endereço - Av. Prefeito Lothário Meissner, n॰ 632 - Térreo - Jardim Botânico

CEP: 80210-170 - Curitiba/PR - Brasil

E-mail: iaravigo@ufpr.br

Telefone: +55 (41) 8449-1752

\section{Willson Gerigk}

Doutor em Políticas Públicas pela Universidade Federal do Paraná

Professor do Curso de Graduação em Ciências Contábeis da Universidade Estadual do

Centro-Oeste - Unicentro

Endereço: Rua Presidente Vargas, n॰22, Bairro Centro

CEP: 84550-000 - Rebouças/PR - Brasil

E-mail: gerigkw@yahoo.com.br

Telefone: +55 (42) 9922-7902

\section{Flávio Ribeiro}

Doutorando em Contabilidade pela Universidade Federal do Paraná

Professor do Curso de Graduação em Ciências Contábeis da Universidade Estadual do Centro-Oeste - Unicentro

Endereço: Rua Pissaia, n॰ 306, Bairro Centro

CEP: 84560-000 - Rio Azul/PR - Brasil

E-mail: flavioribeiro@,irati.unicentro.br

Telefone: + 55 (42) 9937-1835

Artigo recebido em 20/10/2015. Revisado por pares em 08/04/2016. Reformulado em 06/05/2016. Recomendado para publicação em 31/05/2016 por Sandra Rolim Ensslin (Editora Científica). Publicado em 14/06/2016. 


\title{
Resumo:
}

Este artigo analisa as publicações brasileiras em Ciências Contábeis no período de 2009-2014. Para tanto, aborda-se teoricamente o objetivo da Contabilidade enquanto ciência, e a visão de Karl Popper em relação ao desenvolvimento científico. A metodologia do estudo consiste na análise de artigos publicados nos periódicos brasileiros classificados no Qualis/Capes no estrato A, na área de Administração, Ciências Contábeis e Turismo, e que constam da Base Scielo - Ciências Sociais Aplicadas. A seleção dos artigos foi realizada com as seguintes palavras-chave e expressões: contabilidade, teoria da contabilidade, contabilidade gerencial, contabilidade de custos, contabilidade pública/governamental, contabilidade societária, contabilidade financeira, contabilidade ambiental e controladoria, envolvendo o período compreendido entre os anos de 2009 a 2014. Verifica-se que os preceitos popperianos de cientificidade não têm sido empregados, e que teorias existentes e estudos anteriores têm conduzido as pesquisas na área de Ciências Contábeis no Brasil.

Palavras-chave: Karl Popper. Falseabilidade. Teoria da contabilidade. Publicações no Brasil.

\begin{abstract}
This paper analyzes the Brazilian publications on research on Accounting Sciences in the period 2009-2014. For that, the purpose of accounting as a science and Karl Popper's view of scientific development are approached. The methodology of this study is an analysis of articles published in Brazilian journals classified as Qualis/CAPES in stratum A, in the Administration, Accounting and Tourism areas, as present in the Scielo Base - Applied Social Sciences. The selection of articles was performed according to the following keywords and expressions: accounting, accounting theory, management accounting, cost accounting, public accounting/government, corporate accounting, financial accounting, environmental accounting and controlling in the period 2009-2014. The results indicate that the Popperian precepts of scientificity have not been employed and that existing theories and previous studies which have guided researches in Accounting Sciences in Brazil.
\end{abstract}

Keywords: Karl Popper. Falsifiability. Accounting theory. Publications in Brazil

\section{Resumen}

Este artículo analiza las publicaciones brasileñas en Ciencias Contables en el período 20092014. Por lo tanto, se discute teóricamente la Contabilidad como ciencia conforme a la visión de desarrollo científico de Karl Popper. La metodología del estudio es el análisis de los artículos publicados en revistas nacionales clasificadas como Qualis/Capes en el estrato "A" en el área de Administración, Contabilidad y Turismo, contenida en la Base de Scielo Ciencias Sociales Aplicadas. La selección de artículos se lleva a cabo con las siguientes palabras clave y frases: contabilidad, teoría de la contabilidad, contabilidad de gestión, contabilidad de costes, contabilidad pública/gubernamental, contabilidad corporativa, contabilidad financiera, contabilidad ambiental y contraloría, que implica el período comprendido entre años 2009 y 2014. Se concluye que no se usan los preceptos popperianos del cientificismo y que teorías y estudios previos han conducido las investigaciones en las ciencias contables en Brasil.

Palabras clave: Karl Popper. Falsabilidad. Teoría de la contabilidad. Publicaciones en Brasil. 


\section{Introdução}

A contabilidade, assim como outras ciências que atuam em um ambiente muito complexo e dinâmico, necessita permanentemente aperfeiçoar seus fundamentos teóricos com o objetivo de conseguir responder às demandas dos profissionais da área e, também, aprimorar as questões teóricas que têm implicações pragmáticas, tanto para os usuários externos como para os internos da informação contábil.

A contabilidade, segundo Petterson et al. (2009), durante sua evolução histórica procurou adequar-se às necessidades do seu ambiente fornecendo informações úteis para auxiliar gestores e usuários externos nas tomadas de decisão. Em outras palavras, esteve sempre evoluindo historicamente para manter-se cientificamente útil e relevante, atendendo às novas exigências e necessidades que a realidade the imputava.

As pesquisas na área de contabilidade no país vêm, nos últimos anos, estruturando-se por meio do aumento dos programas de pós-graduação, que deveriam contribuir de maneira ativa no desenvolvimento de pesquisas com a finalidade de aplicar, testar e contrapor as teorias que alicerçam a área com as mais diversas realidades empíricas para que, com isso, ocorresse a evolução teórica da área.

O canal qualificado de disseminação dessas pesquisas tem sido os periódicos científicos, que contam com a avaliação da Coordenação de Aperfeiçoamento de Pessoal de Nível Superior (Capes) por meio do sistema Qualis, que consiste em um conjunto de procedimentos utilizados para a estratificação da qualidade da produção intelectual dos programas de pós-graduação. Como resultado, disponibiliza a classificação dos veículos utilizados pelos programas de pósgraduação para a divulgação de suas pesquisas. Dessa forma, o Qualis afere a qualidade dos artigos e de outros tipos de produção intelectual, a partir da análise dos veículos utilizados para a sua divulgação, ou seja, os periódicos científicos (CAPES, 2014).

Entende-se que toda a produção científica desenvolvida nos programa de pós-graduação de contabilidade, e pelos pesquisadores da área tem, como canal qualificado para sua divulgação, os periódicos científicos. Entre estes, para as Ciências Contábeis, destacam-se os classificados nos estratos A1 e A2, da área de Administração, Ciências Contábeis e Turismo.

O desenvolvimento teórico da contabilidade é realizado por meio de pesquisas que objetivem testar as teorias que sustentam a área contábil, contribuindo para sua evolução enquanto ciência. Entretanto, o critério de teste de teorias tem sofrido alterações na história da filosofia da ciência, a qual se profissionalizou no início do século XX, com a escola que passou a ser conhecida como positivismo lógico, e que constituiu um conjunto de ideias desenvolvidas pelo chamado Círculo de Viena. Os pensadores daquela escola, embora com algumas divergências pessoais e posteriores redefinições do critério, começaram por defender que o teste crucial de uma teoria se dava por sua verificabilidade, ou seja, ela seria considerada verdadeira ou falsa conforme seus enunciados e condições se verificassem na realidade. Nesses termos, o princípio da verificabilidade tornava-se um critério de demarcação científica, separando o que era considerado ou não ciência.

Um dos primeiros críticos do positivismo lógico foi Karl Popper. Em seu primeiro livro, A Lógica da Investigação Científica, de 1934, Popper opõe-se ao critério de verificabilidade e defende que o critério deveria ser o falseabilismo. Usando, aqui, um exemplo do próprio Popper, não importava quantos cisnes brancos fossem vistos, ainda sim não poderíamos afirmar que todos os cisnes são brancos. Tanto é que existem cisnes negros 
na Austrália. Assim, o que a ciência deveria perseguir era a falseabilidade da teoria. Se um único cisne negro fosse observado, isto significaria que poderíamos afirmar com certeza que nem todos os cisnes são brancos.

É com base nessas ideias que esse estudo propõe verificar se a teorização em Contabilidade tem utilizado o critério da falseabilidade. A metodologia do estudo consiste na análise de artigos publicados nos periódicos brasileiros classificados no Qualis/Capes como A, na área de Administração, Ciências Contábeis e Turismo, que constam da Base Scielo Ciências Sociais Aplicadas. A coleta de dados deu-se em um total de cinco periódicos, todos A2.

A fim de atender a finalidade exposta, o artigo está organizado da seguinte maneira: após esta introdução, segue a fundamentação teórica sobre os objetivos da Contabilidade enquanto ciência e a visão de Karl Popper em relação ao desenvolvimento científico. $\mathrm{Na}$ sequência é apresentada a metodologia que conduziu a pesquisa. Posteriormente, são apresentados e discutidos os resultados da pesquisa e, por fim, são desenvolvidas as considerações finais.

\section{A Contabilidade enquanto Ciência e a visão de Karl Popper}

\subsection{A contabilidade}

A contabilidade é entendida como a ciência que tem por objeto o patrimônio das entidades, em seus diversos ramos ou segmentos de atuação. Sua finalidade primordial é o subsídio de informações, para a tomada de decisão, aos usuários da informação contábil. A estrutura contábil vigente no Brasil, hoje, é fruto de um trabalho em conjunto de duas das principais entidades contábeis mundiais: o FASB (Financial Accounting Standards Board) e o IASB (International Accounting Standards Board). O FASB é uma entidade privada, criada em meados da década de 1970, responsável pela edição das normas contábeis norteamericana. O IASB também se trata de uma entidade privada, mas de abrangência internacional, que possui mais de 100 países filiados, inclusive o Brasil, e é responsável pela emissão das normas internacionais de contabilidade (IAS e IFRS).

Anterior ao processo de convergência, a estrutura contábil brasileira era amparada pela Resolução CFC n 750/1993, que deliberava sobre os princípios contábeis a serem seguidos. Todavia, para atender as normas internacionais de contabilidade, a referida norma foi modificada pela Resolução CFC $\mathrm{n}^{0} 1.282 / 2010$, e posteriormente passou a ser regida pela Resolução do CFC n ${ }^{\circ} 1.374 / 11$.

O objetivo da informação contábil tem sido amplamente discutido na área da contabilidade. Paton (1922) afirmava que a função da contabilidade e dos princípios e procedimentos contábeis devem ser expostos em termos da necessidade dos proprietários. American Accounting Association, AAA, (1966) descreve que o processo de identificação, mensuração e divulgação da informação contábil permite a realização de julgamento e decisões pelos usuários da informação. O Accounting Principles Board $n^{\circ} 4$, APB, (1970) destaca que a função dos serviços contábeis é fornecer informações quantitativas sobre a entidade, cuja finalidade é permitir a tomada de decisão (HENDRIKSEN; VAN BREDA, 2007). Por fim, o CPC 01 R1 (2011) relata que o objetivo do relatório contábil é fornecer 
informações acerca da entidade, que sejam uteis para que os usuários externos possam tomar suas decisões.

Portanto, verifica-se que a premissa que permeia o objetivo da informação contábil evoluiu com o passar dos anos. Inicialmente a informação se restringia à necessidade dos proprietários da entidade (PATON, 1922). Com o decorrer dos anos, a informação passou a atender os outros usuários externos da contabilidade (AAA, 1966). Outra evolução observada refere-se à característica da informação. Primeiramente, ela se restringia em fornecer informações quantitativas (APB, 1970); porém, atualmente, o grande enfoque das informações passou a ser a característica qualitativa (CPC 00 R1, 2011).

Para Hendriksen e Van Breda (2007), as discussões teóricas sobre os objetivos da contabilidade podem ser resumidas em três níveis, na teoria contábil: 1) sintático; 2) semântico; e 3) pragmático. O nível sintático preocupa-se com a sintaxe ou gramática da contabilidade; o semântico com o significado da linguagem ou sua sintaxe; e o nível pragmático com o emprego da contabilidade junto à realidade, ou seja, os efeitos da linguagem contábil. Outra forma de abordar o debate teórico na área contábil é enfatizar se os argumentos fluem de generalizações a observações específicas (raciocínio dedutivo), ou se partem das observações específicas a generalizações (raciocínio indutivo). Em contabilidade, as generalizações são postulados e, a partir desses, são deduzidos os princípios contábeis que servem de base para as aplicações concretas e práticas.

A teoria da contabilidade tem sido definida como um conjunto coerente de princípios lógicos que: 1) oferecem uma compreensão melhor das práticas existentes a contadores, investidores, administradores e estudantes; 2) oferecem um referencial conceitual para avaliação de práticas contábeis existentes; e 3) orientem o desenvolvimento de novas práticas e novos procedimentos. Porém, a teoria contábil encontra-se em um estágio de evolução enquanto ciência (HENDRIKSEN; VAN BREDA, 2007). Na linha desse entendimento, Bertolucci e Iudícibus (2004) afirmam que, na Ciência Contábil, como em tudo que o homem faz no mundo real, não existe uma resposta perfeita, mas deve ser encarada pelo valor que tem e pelo apoio que pode dar à evolução das ideias, entendidas como desenvolvimento científico. A evolução da ciência pode ser entendida como a prevalência, durante épocas, de uma determinada teoria, a forma de encarar a teoria ou mesmo os paradigmas científicos.

Sob a perspectiva do desenvolvimento científico em contabilidade, alguns autores (CARDOSO et al. 2005; THEOPHILO; IUDÍCIBUS, 2005; MENDONÇA NETO; RICCIO; SAKATA, 2009) têm buscado discutir as características das produções científicas contemporâneas.

Cardoso et al. (2005) analisaram as publicações científicas na área de contabilidade entre os anos de 1990 a 2003, nas revistas qualificadas com conceito A pela Capes, por meio de análise bibliométrica, usando a técnica da Lei de Lotka. Foram avaliados 60 artigos de um total de 2.037 publicados. Os resultados indicaram baixa participação das publicações de área contábil (apenas 2,95\% do total de artigos), concentração das publicações em poucos autores, evidências de baixa contribuição teórica dos artigos com predominância da abordagem quantitativa. Theophilo e Iudícibus (2005) avaliaram a produção científica brasileira na área de contabilidade por meio das teses e dissertações defendidas nos programas de pósgraduação stricto sensu (mestrado e doutorado, embora só a USP tivesse um programa de doutorado na época) recomendados pela Capes de sete IES, dos artigos da Revista Contabilidade e Finanças (único periódico da época com conceito A no Qualis/Capes) e dos artigos publicados no Encontro da Associação Nacional dos Programas de Pós-Graduação em 
Administração - ENANPAD, da área de Contabilidade e Controle Gerencial. Foram analisadas 238 pesquisas entre os anos de 1994 a 2003. Os autores dividiram as análises em dois subperíodos, o primeiro de 1994 a 1998, em que foram avaliados 44 trabalhos; e o segundo compreendendo os anos de 1999 a 2003, em que as análises envolveram 194 trabalhos. Concluíram que, na primeira fase (1994-1998), predominaram os trabalhos teóricos com posturas normativas e que visavam a desenvolver investigações em profundidade para propor novas ideias e visões; na segunda fase, o tipo de trabalho mais frequente foi o teóricoempírico, que apresentava postura teórica positiva e realizava investigações baseadas em teorias existentes e aceitas pela comunidade científica. A pesquisa revelou, também, a dificuldade, por parte dos trabalhos avaliados, de empregar instrumentais metodológicos e da pouca utilização das diversas alternativas metodológicas disponíveis.

Mendonça Neto, Riccio e Sakata (2009) avaliaram os artigos publicados no Encontro da Associação Nacional dos Programas de Pós-Graduação em Administração - ENANPAD de 1996 a 2005, em que, no título, constavam indicações com a área de contabilidade, que totalizaram 405 publicações. A análise foi bibliométrica, usando a técnica da Lei de Lotka. Os resultados revelaram a predominância da pesquisa positiva, a qual foi adotada em $82 \%$ dos trabalhos (333 de 405), em 83\% das participações (745 de 900), e por $81 \%$ dos autores (480 de 596). Quando se inclui os autores que adotaram tanto a abordagem positiva quanto a normativa, o índice sobe para 87\% (520 de 596). Os autores que adotaram exclusivamente a abordagem normativa limitaram-se a $13 \%$ do total (76 de 596). Em termos de evolução temporal, a participação da abordagem positiva passou, de $56 \%$ do total de trabalhos apresentados em 1996 (5 em um total de 9), para 89\% em 2005 (84 em um total de 94).

Portanto, nota-se que as pesquisas em contabilidade ainda são pouco representativas, quando comparadas às demais áreas de estudo (CARDOSO et al. 2005). Observa-se, também, um domínio dos estudos positivistas (MENDONÇA NETO; RICCIO; SAKATA, 2009), bem como um aumento de publicações empíricas, modificando o cenário de publicações contábeis anteriores a 1998, onde predominavam as teóricas (THEOPHILO; IUDÍCIBUS, 2005).

Diferentemente dos estudos supracitados, a presente pesquisa busca avançar no campo dos estudos contábeis, investigando se a teorização em Contabilidade tem utilizado o critério da falseabilidade. A evolução da ciência contábil é considerada com base no entendimento de Karl Popper (1975) a respeito do que consiste a produção de teorias e os critérios da demarcação entre ciência e não ciência. De acordo com Popper, a ciência é aquele corpo de proposições sintéticas sobre o mundo real que pode, pelo menos em princípio, ser falseada mediante observações empíricas, e caracteriza-se pelo seu método de formular e testar proposições (BLAUG, 1993). Em outras palavras, a evolução científica das teorias consiste na busca de sua falseabilidade, diante das realidades que se apresentam no mundo real, representadas por novas ou reformuladas hipóteses de pesquisa.

\subsection{Popper e a falseabilidade das teorias}

Karl Popper foi o primeiro grande crítico do positivismo lógico. Suas contestações a muitos dos fundamentos do movimento, que passou a ser conhecido como visão adquirida ${ }^{1}$,

\footnotetext{
${ }^{1}$ A expressão "visão adquirida" foi utilizada pela primeira vez por Frederick Suppe para designar o positivismo lógico, tal como se desenvolvera nos seus primórdios e que predominara entre as décadas de 1920 e 1950 (BLAUG, 1993, p. 37). 
foram manifestadas ainda na época em que o Círculo costumava se reunir em Viena. Em seu primeiro livro, A Lógica da Investigação Científica, de 1934, Popper opõe-se ao critério de verificabilidade do significado preconizado pelos primeiros neopositivistas, defende o falseabilismo e se contrapõe veementemente ao indutivismo.

Enquanto, para os positivistas lógicos, o enunciado só terá significado quando verificável por indução empírica, Popper questiona a validade da indução no teste das teorias (problema da indução), pois, para ele, as teorias nunca são empiricamente verificáveis, mas devem poder ser sempre falseáveis por testes que procurem refutá-las. As proposições singulares podem falsear as proposições universais. As leis são científicas porque são suscetíveis de serem falseadas. Embora as teorias, através da falseabilidade, fiquem mais instáveis, ao mesmo tempo tornam-se mais confiáveis. Segundo Carvalho (1990, p. 91), para que haja o crescimento do conhecimento é necessário expor as teorias a "uma tensão máxima", sujeitá-las "ao risco da falsificação".

Popper acredita que a observação conduz ao conhecimento do fato, mas não leva ao estabelecimento da verdade de nenhum enunciado. Assim, a ciência não se origina puramente da experiência, mas das colocações de problemas teóricos. É somente em relação a eles que se aceita ou não enunciados básicos acerca da experiência. A ciência não alcança a verdade, é uma empreitada na busca do progresso do conhecimento e da aproximação da verdade. Ela nasce de ideias e é testada pelo experimento conduzido pelas ideias. A teoria é uma ideia testada. O ideal científico do conhecimento absoluto é uma utopia. As teorias científicas mantêm-se "provisórias para sempre" (POPPER, 1980, p. 120-124).

De acordo com Redman (1991, p. 4), desde os anos 1960, a imagem da ciência como um processo racional e cumulativo tem sido bastante questionada. Aqueles fundamentos da ciência do século XVII, baseados na observação e experimentos, não são mais aceitos como critérios seguros. A atenção se volta para a história da ciência, mais exatamente para os seus avanços, ou seja, o crescimento do conhecimento. A clara distinção entre observação e teoria (contexto da descoberta e contexto da justificação) foi considerada inválida. A crença em um método universal, capaz de estabelecer uma ciência unificada, foi abandonada. A visão de que a legitimidade e progresso de uma ciência é proporcional ao emprego de um método que se espelhe na física tem sido considerada ingênua pela maioria dos filósofos. Entretanto, particularmente nas ciências sociais, a concepção de ciência do século XVII tem sido bastante influente. Ao mesmo tempo, as ideias da filosofia da ciência têm tido maior ressonância entre os cientistas sociais.

Para Popper (2006), o critério do estatuto científico de uma teoria é a sua falsificabilidade, ou refutabilidade. A falsificabilidade, isto é, a capacidade de uma teoria poder, em princípio, ser refutada com base na experiência, representa, para Popper, o critério que permite traçar uma linha de demarcação entre ciência (empírica) e não ciência (CARVALHO, 1990). A demarcação refere-se à separação entre os enunciados considerados científicos e os outros enunciados, sejam de caráter religioso, metafísico ou simplesmente pseudocientífico (POPPER, 2006).

$\mathrm{O}$ estabelecimento de regras adequadas à epistemologia ou lógica de pesquisa científica está estreitamente ligado ao critério de demarcação. Para Popper, para que sejam considerados científicos, os enunciados precisam ser passíveis de sujeição à falseabilidade (POPPER, 1975).

A teoria científica é testada quando um cientista especifica, com antecedência, as condições observáveis que poderiam falsear a teoria. Quanto mais exatas as especificações, 
maiores as possibilidades de falseamento da teoria. Porém, se a teoria resistir à falsificação será considerada corroborada, ou seja, não foram encontrados fatos, devidamente especificados, que a refutem (BLAUG, 1993).

Para Popper, os enunciados universais e os básicos ou singulares alicerçam a falseabilidade das teorias. Por enunciado universal entendem-se as teorias gerais que derivam os axiomas, e destes os demais enunciados pertencentes ao sistema teórico (POPPER, 1975). E por enunciado básico ou singular, compreende-se aquele que assevera que um evento observável está ocorrendo em certa região individual do espaço e do tempo (POPPER, 1975).

Uma teoria será chamada de falseável sempre que, sem ambiguidade, dividir a classe de todos os possíveis enunciados básicos em duas classes: 1) a classe de todos os enunciados básicos com os quais é incompatível - que rejeita, ou proíbe - denominados falseadores potenciais; 2) a classe de enunciados básicos que ela não contradiz - que permite, ou aceita. Com base nessa divisão, uma teoria é falseável se contiver a classe de seus falseadores potenciais (POPPER, 1975).

A falseabilidade das teorias está associada a um sistema de enunciados. Uma teoria está falseada somente quando dispomos de enunciados básicos aceitos que a contradiga. Esta é uma condição necessária, porém, não suficiente. Assim, uns poucos enunciados básicos dispersos, que contestem a teoria, dificilmente levarão a sua falseabilidade. Somente se aceita a falseabilidade da teoria se uma hipótese falseadora for proposta e corroborada (POPPER, 1975).

O que é importante notar é que nem sempre a substituição de uma teoria por outra pode ser interpretada como uma autêntica revolução científica. Nem sempre a suplantação de teorias adquire o significado de uma mudança de paradigma. Ocorre, às vezes, que uma teoria válida para um âmbito relativamente restrito da realidade é suplantada por outra, mais abrangente, que passa a acolhê-la, sem que a teoria emergente afronte os fundamentos da sua antecessora (CARVALHO, 1990). Uma teoria científica revela sua cientificidade exatamente na medida em que pode se mostrar incompatível com a experiência, na medida em que pode se revelar falsa (CARVALHO, 1990).

Para Popper, a ciência desenvolve-se a partir de revoluções constantes, renovando-se permanentemente. Toda teoria é sempre provisória. O critério de falseabilidade está associado à ideia de movimentação e rupturas de paradigmas científicos, ao contrário do verificacionismo, que tem como princípio básico a ideia de verdade. O falseacionismo não pressupõe uma verdade primeira, mas um enunciado seguido de uma contraprova ou de sua falseação. A ideia é a de que a ciência ou o conhecimento científico se desenvolve a partir da busca e da tentativa de encontrar lacunas para falsear uma teoria. Nesse caso, os cientistas desenvolveriam teorias (métodos) cada vez mais consistentes e flexíveis, pois contariam com o princípio da incerteza e das mudanças de paradigmas, e essas mudanças seriam constantes (FRANCELIN, 2004).

\section{Pesquisas em Contabilidade no Brasil de 2009-2014 e o Falseabilismo de Popper}

A finalidade desse estudo é verificar se as pesquisas brasileiras na área de Ciências Contábeis têm adotado o critério popperiano do falseabilismo. Isto é, se as pesquisas têm procurado falsear as teorias existentes ou, caso contrário, têm buscado sua confirmação. 
Quanto aos objetivos, o estudo caracteriza-se por ser essencialmente descritivo. O estudo emprega pesquisa bibliográfica e documental, e a abordagem é predominantemente qualitativa.

Os artigos analisados são da área de Administração, Ciências Contábeis e Turismo, conforme definição da Capes. A partir de uma listagem inicial dos periódicos da área, foram selecionados aqueles enquadrados no estrato A. Este recorte tem por objetivo analisar os artigos que se encontram nos periódicos com maior Fator de Impacto no meio acadêmico. E o período de análise envolveu os anos de 2009 a 2014.

Os periódicos foram selecionados na base Scielo. De um total de 34 periódicos da área, 5 (cinco) periódicos foram categorizados no estrato A e continham publicações entre os anos de 2009 a 2014 com as palavras-chave empregadas na pesquisa, sendo esses: Revista de Administração Contemporânea (RAC), Revista de Administração de Empresas (RAE), Revista de Administração Pública (RAP), Revista de Administração São Paulo (RAUSP) e a Revista Contabilidade \& Finanças (RCF). Os cinco periódicos são classificados como A2.

A seleção dos artigos deu-se utilizando as seguintes palavras-chave: contabilidade, teoria da contabilidade, contabilidade gerencial, contabilidade de custos, contabilidade pública/governamental, contabilidade societária, contabilidade financeira, contabilidade ambiental e controladoria, por entendermos serem estes os termos que mais se referem à ciência da contabilidade. O objetivo fundamental do trabalho é avaliar como as pesquisas em contabilidade estão testando suas teorias e, em particular, se estão usando o critério de falsificabilidade de Popper. Assim, consideramos que os termos mencionados como mais adequados. Seguindo o recorte proposto neste estudo, foram selecionados e analisados 28 (vinte e oito) artigos.

Os artigos selecionados, os quais constam no Apêndice A, foram analisados quanto: aos objetivos, ao problema central, à definição de hipóteses, à metodologia e técnica de análise empregada e às suas principais conclusões e achados. 


\begin{tabular}{|c|c|}
\hline \multicolumn{2}{|c|}{ Figura 1 - Procedimentos empregados nesta pesquisa } \\
\hline \multicolumn{2}{|c|}{$\begin{array}{l}\text { Exis te fals eabilidade nas pesquis as em contabilidade? } \\
\text { Esque ma para o des envolvimento da pesquis a }\end{array}$} \\
\hline \multicolumn{2}{|r|}{ 1. Escolha dos períodicos } \\
\hline Pesquisa na Capes - Qualis & $\begin{array}{l}\text { Listagem dos periódicos }=\text { Área Administração, Contabilidade e Turismo } \\
\text { Total de } 34 \text { periódicos }\end{array}$ \\
\hline \multicolumn{2}{|r|}{ 2. Es colha dos artigos } \\
\hline $\begin{array}{l}\text { Periodicos com Qualis A, da Base Scielo } \\
5 \text { periódicos - Área: Ciências Sociais Aplicadas } \\
\text { Período: } 2009 \text { a } 2014 \\
\text { Artigos analisados: } 28 \text { (vinte e oito) }\end{array}$ & $\begin{array}{l}\text { Busca, nas páginas dos periódicos, de artigos com termos (palavras-chave): } \\
\text { 1.Contabilidade - 2.Teoria da Contabilidade - 3.Contabilidade Gerencial } \\
\text { 4.Contabilidade de Custos - 5.Contabilidade Pública/Governamental - } \\
\text { 6.Contabilidade Societária - 7.Contabilidade Financeira - } \\
\text { 8.Contabilidade Ambiental - 9.Controladoria. }\end{array}$ \\
\hline \multicolumn{2}{|c|}{ 3. Caracterização dos artigos } \\
\hline \multicolumn{2}{|c|}{$\begin{array}{l}\text { Análise dos artigos selecionados, de acordo com os seguintes ascpectos: periódico, autor(es), ano de publicação, instituição } \\
\text { autores e co-autores, definição de problema e hipóteses, método e técnica empregada e análise semântica do objetivo. }\end{array}$} \\
\hline \multicolumn{2}{|c|}{ 4. Análise envolvendo o objetivo e a te oria da fals eabilidade de Popper } \\
\hline \multicolumn{2}{|c|}{$\begin{array}{l}\text { Analisar se as conclusões ou achados do(s) autor(es) refuta }(\mathrm{m}) \text { os achados anterioriores, levando em conta os objetivos da } \\
\text { pesquisa ou se as conclusões reforçam o que anteriormente existia. }\end{array}$} \\
\hline \multicolumn{2}{|c|}{ 5. Organização das informações produzidas } \\
\hline Elaboração & um panorama geral do período analisado \\
\hline
\end{tabular}

Fonte: Elaborado pelos autores.

Diante das informações disponíveis e da forma de construção da análise deste estudo, observa-se limitação em relação ao número de artigos e periódicos analisados, mesmo utilizando palavras-chave que representam grandes áreas de Ciências Contábeis.

O objetivo deste estudo é analisar se as teorias existentes nas Ciências Contábeis, e em suas diversas subáreas, vêm sendo falseadas ou corroboradas em pesquisas recentes, considerando a metodologia definida na Figura 1. O Gráfico 1 apresenta o total de artigos pesquisados por periódicos, e a Tabela 1 mostra os artigos por temáticas de seleção e por periódico.

Gráfico 1 - Total de artigos pesquisados por periódico - período 2009 a 2014

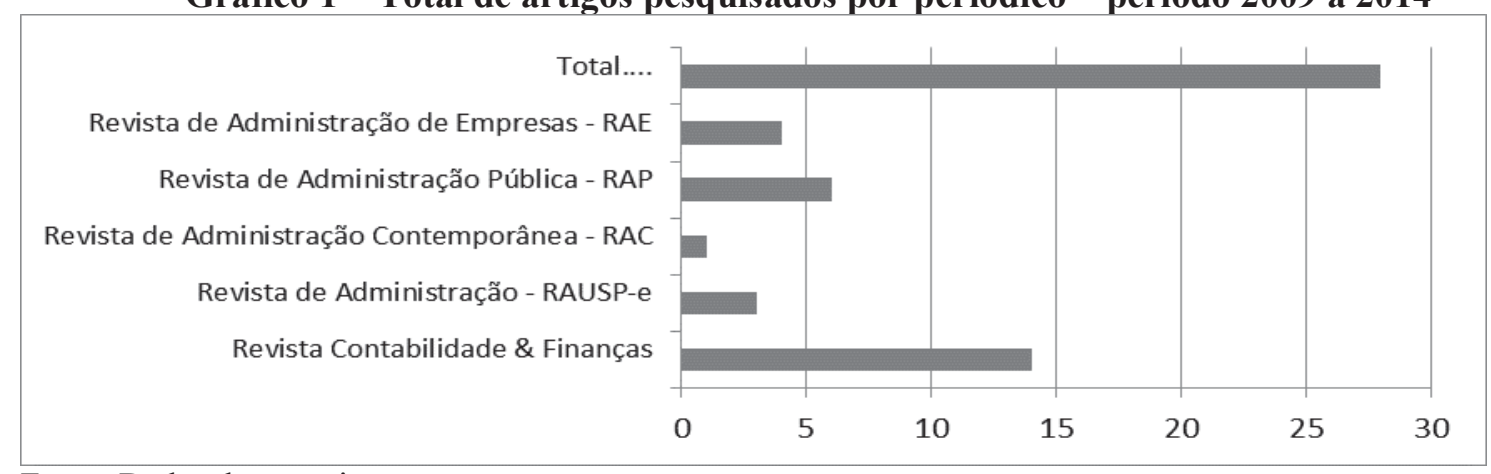

Fonte: Dados da pesquisa. 
Com base no critério de seleção dos periódicos com classificação A1 ou A2, pela Capes, na área Administração, Ciências Contábeis e Turismo e na base Scielo, existem oito periódicos na estratificação utilizada. Porém, três periódicos (Brazilian Administration Review, Organizações \& Sociedade e Revista Brasileira de Economia) não apresentaram artigos com as palavras-chave empregadas no estudo dentro do período coberto pela pesquisa.

Com essas considerações, foram analisados: 14 artigos da Revista Contabilidade \& Finanças/USP, 06 da Revista de Administração Pública/FGV-RJ, 04 da Revista de Administração de Empresas/FGV-SP, 03 da Revista de Administração/USP e 01 artigo da Revista de Administração Contemporânea/RAC, totalizando 28 artigos analisados.

Tabela 1 - Artigos por temáticas de seleção e por periódico - período 2009 a 2014

\begin{tabular}{|c|c|c|c|c|c|}
\hline & Contabilidade & $\begin{array}{c}\text { Teoria da } \\
\text { Contabilidade }\end{array}$ & $\begin{array}{c}\text { Contabilidade } \\
\text { Gerencial }\end{array}$ & $\begin{array}{c}\text { Contabilidade } \\
\text { de Custos }\end{array}$ & $\begin{array}{c}\text { Contabilidade } \\
\text { Pública }\end{array}$ \\
\hline Revista Contabilidade \& Finanças & 8 & 0 & 3 & 0 & 0 \\
\hline Revista de Administração - RAUSP-e & 0 & 0 & 0 & 1 & 0 \\
\hline Revista de Administração Contemporânea - RAC & 0 & 0 & 1 & 0 & 0 \\
\hline Revista de Administração Pública - RAP & 0 & 1 & 0 & 1 & 4 \\
\hline Revista de Administração de Empresas - RAE & 1 & 0 & 2 & 0 & 1 \\
\hline \multirow[t]{2}{*}{ Total.... } & 9 & 1 & 6 & 2 & 5 \\
\hline & $\begin{array}{c}\text { Contabilidade } \\
\text { Societária }\end{array}$ & $\begin{array}{c}\text { Contabilidade } \\
\text { Financeira } \\
\end{array}$ & $\begin{array}{c}\text { Contabilidade } \\
\text { Ambiental }\end{array}$ & Controladoria & Total \\
\hline Revista Contabilidade \& Finanças & 1 & 0 & 0 & 2 & 14 \\
\hline Revista de Administração - RAUSP-e & 0 & 0 & 0 & 2 & 3 \\
\hline Revista de Administração Contemporânea - RAC & 0 & 0 & 0 & 0 & 1 \\
\hline Revista de Administração Pública - RAP & 0 & 0 & 0 & 0 & 6 \\
\hline Revista de Administração de Empresas - RAE & 0 & 0 & 0 & 0 & 4 \\
\hline $\begin{array}{l}\text { Total.... } \\
\end{array}$ & 1 & 0 & 0 & 4 & 28 \\
\hline
\end{tabular}

Fonte: Dados da pesquisa.

Conforme se observa pela Tabela 1, não houve publicação de artigos nas revistas consultadas, entre os anos de 2009 a 2014, que contivessem as palavras-chave contabilidade societária, contabilidade financeira e contabilidade ambiental. Com os demais termos constataram-se: 9 artigos com o termo contabilidade, 6 com contabilidade gerencial, 5 com contabilidade pública, 4 com controladoria, 2 com contabilidade de custos e 1 artigo com teoria da contabilidade e contabilidade societária.

A Revista Contabilidade \& Finanças da USP concentra 9 artigos com o termo contabilidade, e nenhum com a expressão teoria da contabilidade. Já a Revista de Administração Pública (RAP) publicou 4 dos 5 os artigos com o termo contabilidade pública e conta, ainda, com o único artigo que tem o termo teoria da contabilidade. No Gráfico 2 é evidenciada, por periódico, a quantidade de artigos em que seus autores definiram um problema a ser pesquisado, assim como daqueles que não o definiram.

No Gráfico 2 observa-se que, em doze (12) artigos, seus autores não definiram um problema para orientar suas pesquisas, o que representa $42,8 \%$ do total de trabalhos selecionados para análise. Assim, em dezesseis (16) artigos, seus autores orientaram as pesquisas com a finalidade de responder a um questionamento ou lacuna em relação à área de contabilidade, definindo um problema que a pesquisa procurou responder. 
Gráfico 2 - Artigos que definiram problema de pesquisa - 2009 a 2014

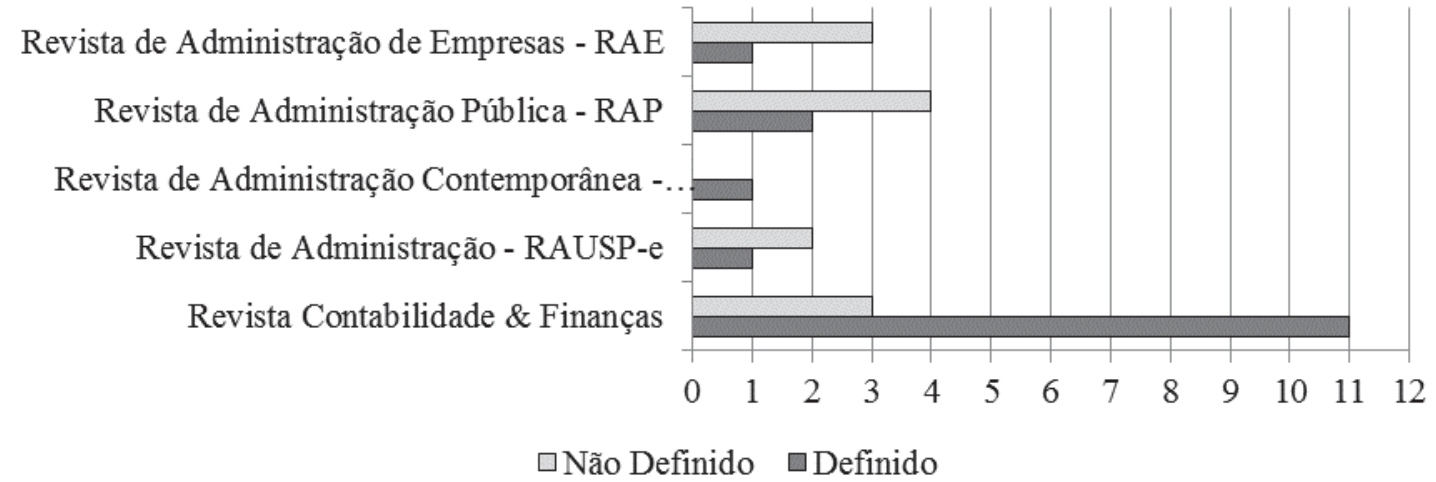

Fonte: Dados da pesquisa.

Outro aspecto procurado nos artigos foi a definição de hipótese para a pesquisa. $\mathrm{O}$ Gráfico 3 apresenta os resultados por periódico.

\section{Gráfico 3 - Artigos que definiram hipótese(s) de pesquisa - 2009 a 2014}

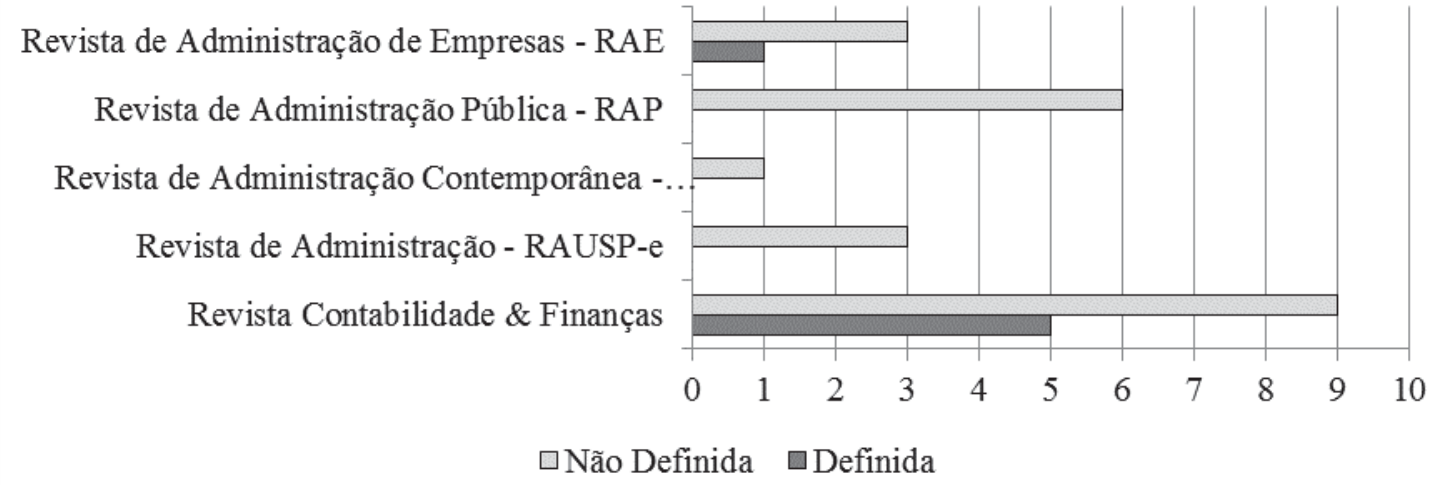

Fonte: Dados da pesquisa.

Percebe-se, pelo Gráfico 3 que, pelos menos no período analisado, a definição de hipótese nas pesquisas publicadas não parece ser uma prática usual, pois, do total de 28 artigos analisados, apenas em 6 (seis) deles seus autores definiram pelo menos uma hipótese norteadora para as pesquisas, e essa prática somente foi constatada nos artigos da Revista Contabilidade \& Finanças e da RAE/FGV.

A metodologia utilizada nas pesquisas é de suma importância para o cumprimento de seus objetivos e à consequente solução do problema pesquisado. O Gráfico 4 apresenta a declaração dos autores quanto à metodologia. 
Gráfico 4 - Metodologia de análise indicada pelos autores em suas pesquisas - 2009 a 2014

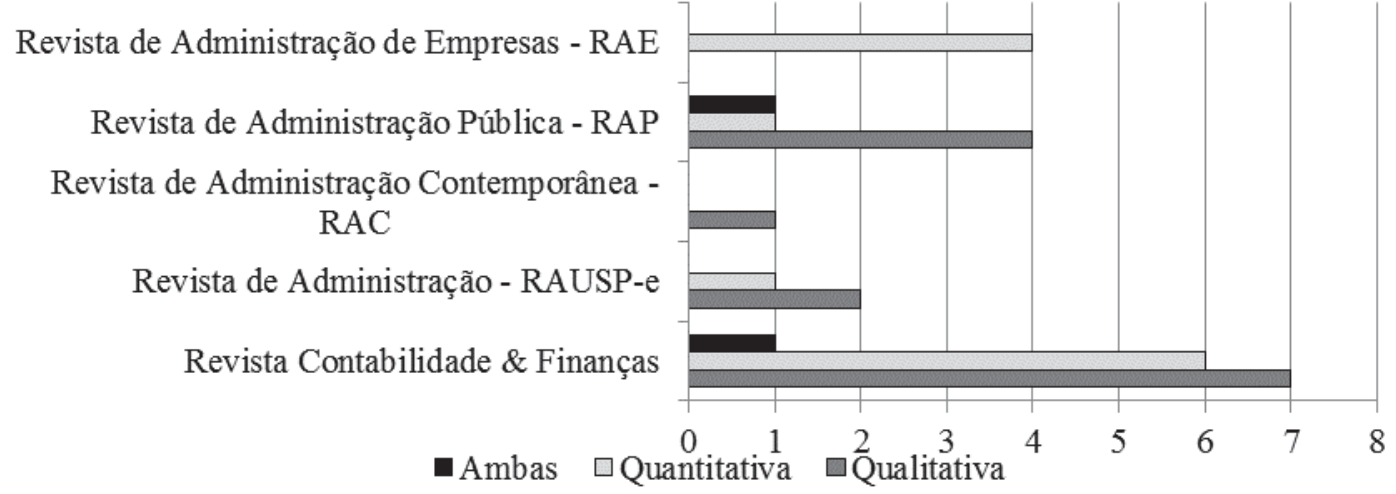

Fonte: Dados da pesquisa.

A caracterização da metodologia deu-se em função da abordagem da pesquisa e pautou-se na indicação expressa pelos autores em seus artigos. Em 14 artigos, os autores caracterizaram suas pesquisas como qualitativas; em 12 artigos, a caracterização foi como quantitativa; e em dois artigos, a metodologia conjugou a abordagem quali-quanti. $\mathrm{O}$ cruzamento entre os dados sobre a metodologia e sobre a não definição do problema de pesquisa mostra que: sete pesquisas declaradas pelos autores como qualitativas estão entre aquelas que não definiram problema de pesquisa; quatro quantitativas estão nessa situação e uma, que declara usar ambas as abordagens metodológicas, também não tem problema de pesquisa.

Aprofundando a questão metodológica, na Tabela 2 são apresentadas as técnicas de análise utilizadas nos artigos pesquisados, por periódico, englobando o período de 2009 a 2014.

Tabela 2 - Técnica de análise utilizada nas pesquisas - 2009 a 2014

\begin{tabular}{|c|c|c|c|c|}
\hline \multirow[b]{2}{*}{ Periódicos } & \multicolumn{4}{|c|}{ Técnica de Análise } \\
\hline & $\begin{array}{l}\text { Estatística } \\
\text { Descritiva }\end{array}$ & $\begin{array}{c}\text { Estatísitca } \\
\text { Multivariada }\end{array}$ & $\begin{array}{c}\text { Estatística Não } \\
\text { Paramétrica }\end{array}$ & $\begin{array}{c}\text { Estudo de } \\
\text { Caso }\end{array}$ \\
\hline Revista Contabilidade \& Finanças & 2 & 5 & 1 & 4 \\
\hline Revista de Administração - RAUSP-e & & 1 & & 1 \\
\hline Revista de Administração Contemporânea - RAC & 1 & & & \\
\hline Revista de Administração Pública - RAP & & 1 & & \\
\hline Revista de Administração de Empresas - RAE & 1 & 1 & 1 & \\
\hline \multirow[t]{2}{*}{$\begin{array}{c}\text { Total.... } \\
\end{array}$} & 4 & 8 & 2 & 5 \\
\hline & \multicolumn{4}{|c|}{ Técnica de Análise } \\
\hline Periódicos & $\begin{array}{l}\text { Ensaio } \\
\text { Teórico }\end{array}$ & Survey & $\begin{array}{c}\text { Análise } \\
\text { Bibliométrica }\end{array}$ & $\begin{array}{c}\text { Estudo } \\
\text { Comparado }\end{array}$ \\
\hline Revista Contabilidade \& Finanças & 1 & 1 & & \\
\hline Revista de Administração - RAUSP-e & 1 & & & \\
\hline \multicolumn{5}{|l|}{ Revista de Administração Contemporânea - RAC } \\
\hline Revista de Administração Pública - RAP & 2 & 2 & & 1 \\
\hline Revista de Administração de Empresas - RAE & & & 1 & \\
\hline $\begin{array}{l}\text { Total.... } \\
\end{array}$ & 4 & 3 & 1 & 1 \\
\hline
\end{tabular}

Fonte: Dados da pesquisa. 
Percebe-se, pelos dados da Tabela 2, que a estatística é um das técnicas mais empregadas nas pesquisas analisadas, estando presente em 14 artigos. E a estatística multivariada é a que predomina entre as técnicas estatísticas, com oito artigos, e desses, cinco não têm hipótese de pesquisa, e dois deles figuram entre aqueles em que seus autores não definiram o problema de pesquisa.

A técnica de estudo de caso está em cinco artigos; o ensaio teórico, em quatro artigos; a utilização de survey é usada em três deles; e a análise bibliométrica e o estudo comparado foram utilizados nas duas pesquisas restantes.

O estudo caracterizou a rede de cooperação formada entres os autores e coautores com base nos periódicos, nos termos de pesquisa utilizados para selecionar os artigos e no período em que se estendeu a pesquisa. Segundo Wasserman e Faust (1994), a rede de autores que publicam nos periódicos representa a troca de informação entre os pesquisadores que representam regularidade. Com base nessa definição de rede de autores, a Figura 2 evidencia a rede de cooperação entre os autores e coautores no período de 2009 a 2014.

Figura 2 - Rede de cooperação entre os autores - período 2009 a 2014

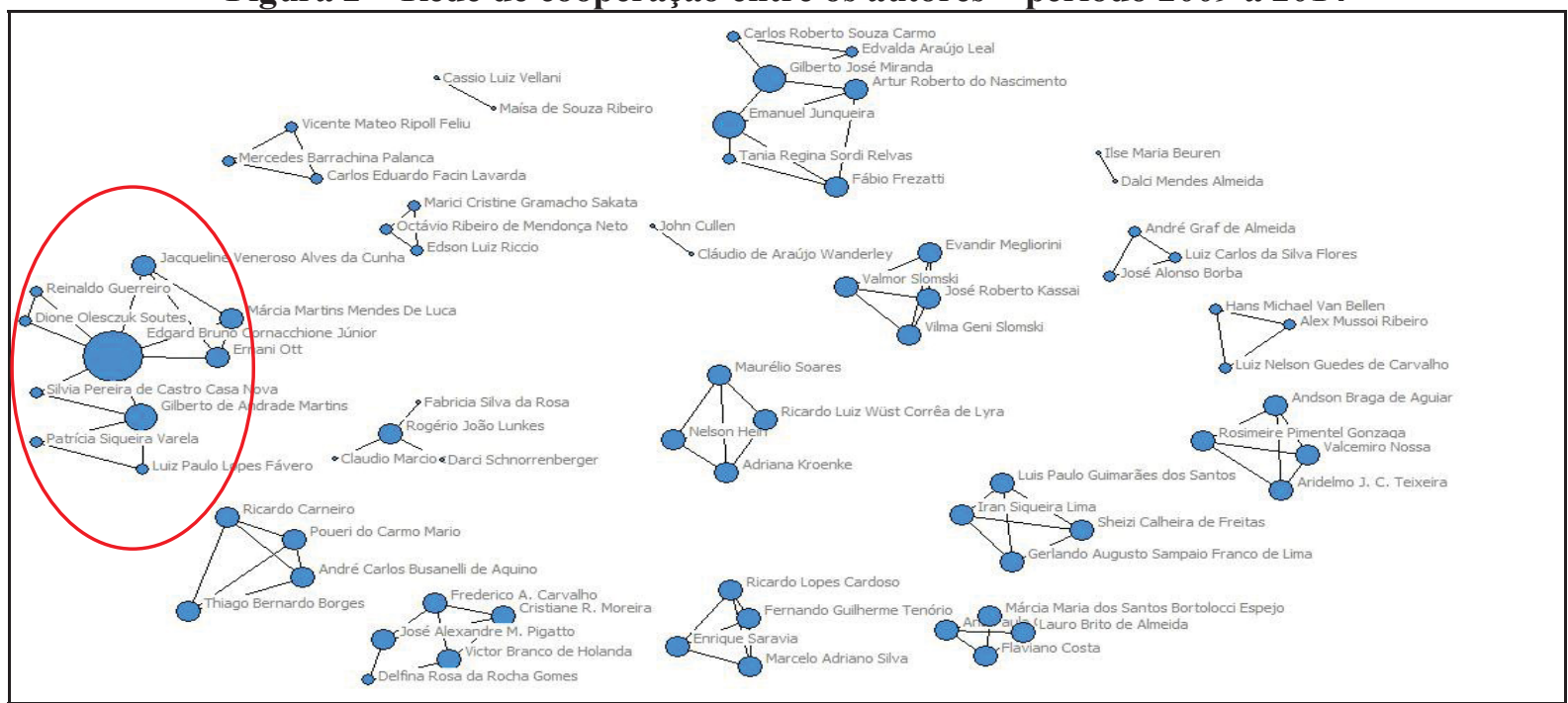

Fonte: Dados da pesquisa.

Os autores e coautores constituíram várias redes dispersas. Porém, é possível destacar um nó em especial, constituído pelos autores Edgard Bruno Cornacchione Júnior; Jacqueline Veneroso Alves da Cunha, Márcia Martins Mendes de Luca; Ernani Ott; Reinaldo Guerreiro; Silvia Pereira de Castro Casa Nova; Luiz Paulo Lopes Fávero; Gilberto de Andrade Martins e Dione Clesczuk Soute, que representam a maior rede de cooperação. A Tabela 3 apresenta os nove autores com maior número de laços diretos em publicações analisadas.

Em relação à centralidade dos laços entre os autores, destaca-se o autor Edgard Bruno Cornacchione Júnior, que apresenta o maior numero de laços diretos (7), seguido por Emanuel Junqueira (6), Poueri do Carmo Mário (5), Ricardo Carneiro (5) e Thiago Bernardo Borges (5). Os autores Gilberto José Miranda, Artur Roberto do Nascimento, Fabio Frezatti e Gilberto de Andrade Martins apresentam individualmente quatro laços cada. 
Tabela 3 - Centralidade dos laços entre os autores

\begin{tabular}{l|c|c}
\hline \multicolumn{1}{c|}{ Autores } & Instituição & Laços diretos \\
\hline Edgard Bruno Cornacchione Júnior & USP/SP & 7 \\
\hline Emanuel Junqueira & UFES/ES & 6 \\
\hline Poueri do Carmo Mario & UFMG/MG & 5 \\
\hline Ricardo Carneiro & FJP/MG & 5 \\
\hline Thiago Bernardo Borges & IBMEC/MG & 5 \\
\hline Gilberto José Miranda & UFU/MG & 4 \\
\hline Artur Roberto do Nascimento & UEFS/BA & 4 \\
\hline Fábio Frezatti & USP/SP & 4 \\
\hline Gilberto de Andrade Martins & USP/SP & 4 \\
\hline Fonte: Dados da pesquisa
\end{tabular}

Fonte: Dados da pesquisa.

A Figura 3 apresenta a rede envolvendo as instituições às quais os autores e co-autores declaram manter vínculo institucional.

Figura 3: Rede das instituições dos autores e coautores - período 2009 a 2014

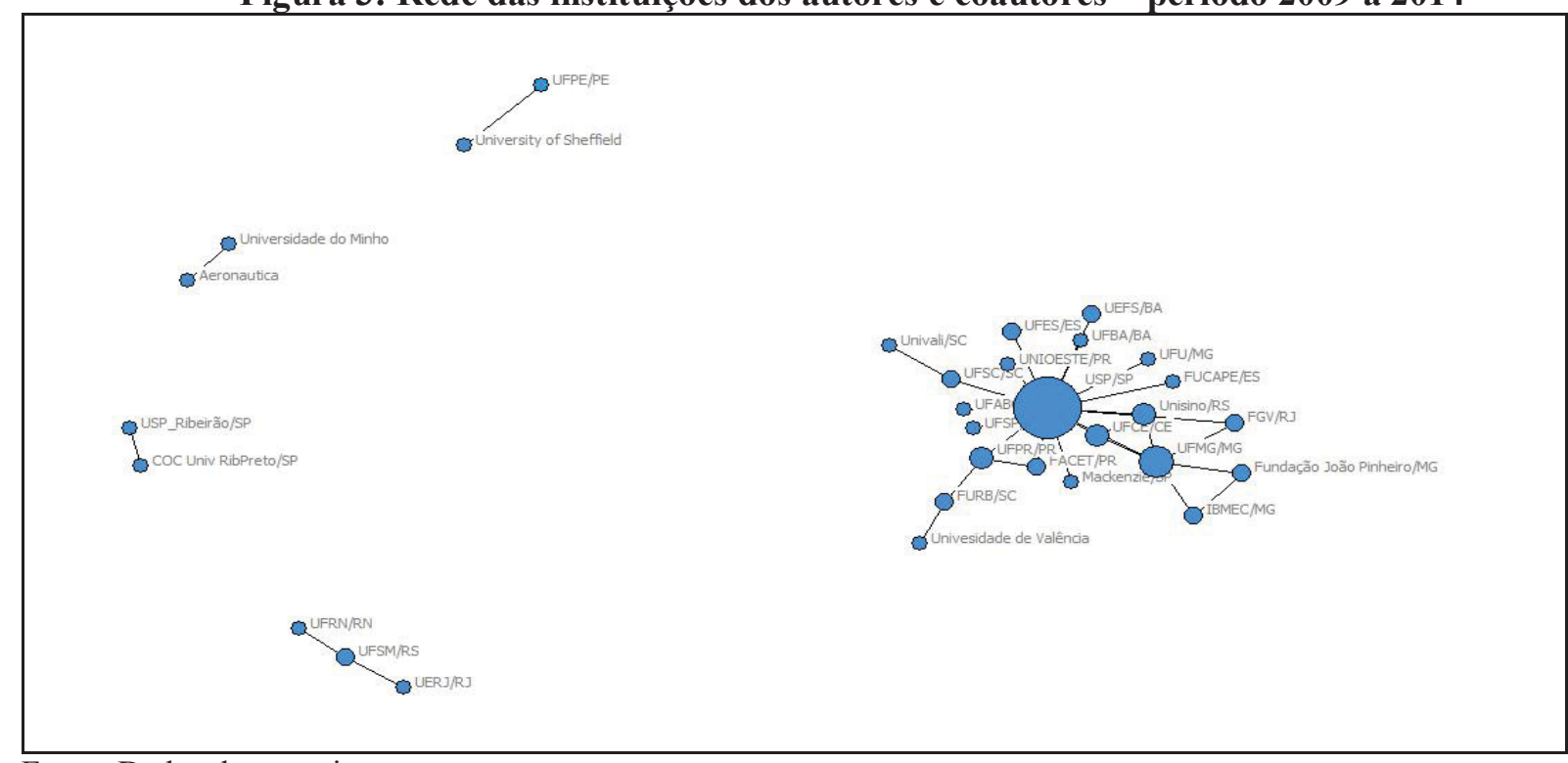

Fonte: Dados da pesquisa.

Sob a perspectiva das instituições de ensino, observa-se grande predominância de publicações proveniente de autores vinculados à Universidade de São Paulo (USP), dezesseis ao todo, ou seja, aproximadamente $57 \%$ da amostra. A USP é quem estrutura a maior rede de cooperação entre os autores e coautores, com 24 laços diretos, formando uma rede com vinte e duas instituições, de um total de trinta e três. Essa concentração pode ser explicada, em parte, pelo fato de seu programa de pós-graduação, mestrado e doutorado em contabilidade ser o mais antigo em funcionamento no país.

A Tabela 4 apresenta a centralidade dos laços entre as instituições de ensino superior. 
Tabela 4 - Centralidade dos laços entre as instituições de ensino

\begin{tabular}{l|c|c}
\hline \multicolumn{1}{c|}{ Instituições } & Laços & \% \\
\hline \hline USP/SP & 24 & $27,27 \%$ \\
\hline UFMG & 7 & $7,95 \%$ \\
\hline UFES & 4 & $4,55 \%$ \\
\hline UFPR & 4 & $4,55 \%$ \\
\hline UEFS & 3 & $3,41 \%$ \\
\hline FURB & 3 & $3,41 \%$ \\
\hline Unisinos & 3 & $3,41 \%$ \\
\hline UFCE & 3 & $3,41 \%$ \\
\hline Outras & 37 & $42,05 \%$ \\
\hline \hline Total & $\mathbf{8 8}$ & $\mathbf{1 0 0 , 0 0 \%}$ \\
\hline \hline
\end{tabular}

Fonte: Dados da pesquisa.

Nota-se que aproximadamente $27 \%$ dos laços formados pelos autores e coautores é constituído por pesquisadores oriundos da USP. Número esse bem superior às demais instituições: UFMG (7); UFES (4); UFPR (4); UEFS (3); FURB (3); Unisinos (3); UFCE (3). Cerca de $42 \%$ dos laços restantes é constituído pelas vinte e cinco instituições.

A Tabela 5 apresenta os termos semânticos utilizados pelos autores na definição de seus objetivos de pesquisa. Na sequência, busca-se vincular a semântica empregada com os resultados alcançados pelos autores.

Tabela 5: Termos semânticos utilizados nos objetivos das pesquisas analisadas

\begin{tabular}{|c|c|c|c|c|c|c|c|}
\hline \multirow{2}{*}{ Periódicos } & \multicolumn{6}{|c|}{ Objetivo da Pesquisa } & \multirow[b]{2}{*}{ Conhecer } \\
\hline & Verificar & Avaliar & Analisar & Comparar & Investigar & Identificar & \\
\hline Revista Contabilidade \& Finanças & & 3 & 3 & 1 & 3 & 2 & \\
\hline Revista de Administração - RAUSP-e & 1 & & 1 & & & & \\
\hline Revista de Administração Contemporânea - RAC & & & & & & 1 & \\
\hline Revista de Administração Pública - RAP & & & 3 & & & & \\
\hline Revista de Administração de Empresas - RAE & 1 & & 1 & & 1 & & 1 \\
\hline Total.... & 2 & 3 & 8 & 1 & 4 & 3 & 1 \\
\hline \multirow{2}{*}{ Periódicos } & \multicolumn{6}{|c|}{ Objetivo da Pesquisa } & \\
\hline & Construir & Levantar & Delinaer & Explicar & Discutir & Demonstrar & \\
\hline Revista Contabilidade \& Finanças & & & 1 & 1 & & & \\
\hline Revista de Administração - RAUSP-e & 1 & & & & & & \\
\hline Revista de Administração Contemporânea - RAC & & & & & & & \\
\hline Revista de Administração Pública - RAP & & 1 & & & 1 & 1 & \\
\hline Revista de Administração de Empresas - RAE & & & & & & & \\
\hline Total.... & 1 & 1 & 1 & 1 & 1 & 1 & \\
\hline
\end{tabular}

Fonte: Dados da pesquisa.

Observa-se que o termo mais usado individualmente para caracterizar o significado do objetivo da pesquisa foi analisar, empregado em oito dos vinte e oito artigos, seguido de 
investigar, usado em quatro artigos; depois avaliar e identificar, que são usados em três artigos cada um dos termos. Na sequência, verificar aparece em dois, e os demais em um artigo cada. Entretanto, se tratarmos os termos semanticamente, podemos considerar que, com exceção dos termos construir e conhecer, os objetivos definidos nos artigos pesquisados buscam resultados com base em pressupostos anteriormente estabelecidos pelas teorias ou pesquisas da área.

A Tabela 6 resume as principais conclusões ou considerações finais dos artigos pesquisados, com o intuito de verificar se as pesquisas analisadas, com base na metodologia estabelecida neste artigo, contribuíram para o avanço da teoria na área de contabilidade, segundo os preceitos popperianos de evolução das teorias.

Tabela 6 - Conclusões ou considerações finais dos artigos pesquisados - 2009 a 2014

\begin{tabular}{l|c|c}
\hline \multicolumn{1}{c|}{ O que indicam } & Qtdade & $\%$ \\
\hline Propõe avanço teórico ao tema pesquisado & 3 & $11 \%$ \\
Os resultados confirmam pesquisas anteriores & 5 & $18 \%$ \\
Empregam teorias existentes para explicar seus resultados & 12 & $43 \%$ \\
Comparam os resultados da pesquisa com os de outras pesquisas & 2 & $7 \%$ \\
Os resultados descrevem perfis (artigos, pesquisas, participantes) & 5 & $18 \%$ \\
Análise empírica sem indicar evolução teórica & 1 & $4 \%$ \\
\hline \multicolumn{1}{c|}{ Total ... } & 28 & $100 \%$ \\
\hline
\end{tabular}

Fonte: Dados da pesquisa.

As conclusões ou considerações finais dos artigos analisados revelam que as pesquisas, entre 2009 a 2014, dos principais periódicos da área de contabilidade, não têm proposto a falsificação das teorias existentes visando a sua evolução, como defendido por Popper, mas que os achados das pesquisas têm, majoritariamente (68\%), empregado teorias e/ou pesquisas existentes para confirmar, explicar ou comparar os resultados das novas pesquisas realizadas.

Uma pequena quantidade, três artigos (11\%), propõe avanço teórico ao tema ou área em que as pesquisas foram desenvolvidas. Porém, mesmo nesses casos, os avanços estão baseados em teorias já existentes, não propondo um repensar delas, mas seu complemento. Os restantes $22 \%$ dos artigos analisados têm, por finalidade principal, descrever e comparar perfis de determinados grupos ou objetos analisados, baseando-se em teorias existentes ou em resultados de pesquisas anteriores.

\section{Considerações Finais}

A finalidade principal dessa pesquisa foi trazer, para discussão, a questão da falseabilidade das teorias na área de contabilidade, conforme defendida por Karl Popper. Procurou-se, com base na metodologia empregada, em analisar se as pesquisas disseminadas nos principais periódicos da área têm contribuído com a teoria contábil, segundo os preceitos popperianos de evolução das teorias.

Diante dos resultados aqui apresentados, levando em conta a metodologia utilizada, pode-se considerar que a área de contabilidade não utiliza o fundamento da falseabilidade das teorias de Karl Popper para contribuir para a evolução teórica da área ou das pesquisas. O que 
comumente encontra-se nas pesquisas nacionais é a ratificação das teorias existentes e dos achados em pesquisas anteriores, em geral pesquisas estrangeiras que são replicadas em um novo contexto.

A análise semântica dos termos usados para estabelecer os objetivos dos artigos pesquisados neste estudo já demonstrava o que, provavelmente, seria encontrado nos resultados dessas pesquisas, ou seja, a principal finalidade seria comparar os novos resultados encontrados com os pressupostos teóricos estabelecidos em teorias ou pesquisas anteriores.

Observa-se, também, que a Universidade de São Paulo (USP) concentrou, por meio dos autores e coautores, as publicações analisadas. Se considerarmos que o seu programa de controladoria e contabilidade, tanto de mestrado quanto de doutorado, são os mais antigos em funcionamento no país, podemos avaliar que, indiretamente, sua concentração seria ainda maior, devido aos autores que passaram pelos referidos cursos e que passaram a desenvolver suas atividades em outras IES. Nesse sentido, pode-se cogitar que a tendência em relação à forma como as pesquisas analisadas foram desenvolvidas, durante o período de análise, seguem o pensamento dos pesquisadores formados na USP, pois detêm $27,27 \%$ dos laços centrais que formaram a rede de pesquisadores abordada neste estudo (Tabela 4).

A não definição de hipótese(s) nas publicações avaliadas parece ser uma prática recorrente, visto que, dos 28 artigos, somente 6 definiram pelos menos uma hipótese a ser testada. O que chama ainda mais a atenção ou preocupação sobre esta questão é que, em doze artigos, o(s) autor(es) declararam que a pesquisa era quantitativa e, para mais dois artigos, seus autores indicaram que as pesquisas envolveriam abordagens quali-quanti. Em outras palavras, metade dos artigos analisados nesta pesquisa declara utilizar a abordagem quantitativa em suas pesquisas; porém, mais da metade desse grupo não define uma hipótese a ser testada pelas técnicas estatísticas, o que indica uma contradição metodológica, pois, com o emprego das técnicas estatísticas busca-se aceitar ou refutar a(s) hipótese(s) a ser(em) testada(s).

Apenas quatro artigos, conforme indicado pelos autores, propuseram avanço teórico ao tema abordado. O primeiro discute, na área de contabilidade ambiental, melhorias no sistema contábil para a gestão da eco eficiência por meio da geração de informações sobre o caminho para a empresa integrar desempenho ecológico e econômico, apontando uma rota para a contabilidade ambiental evoluir. $O$ segundo aborda a necessidade de redução das externalidades negativas do descarte de produtos, propondo a internalização dos custos decorrentes e de criação de créditos de internalização de custos privados (CICP). Isto um título que seria comercializado com o objetivo de viabilizar o processo de coleta e destinação final de todo o lixo doméstico das cidades com a participação plena das empresas. O terceiro artigo é da área pública, e teve como objetivo construir uma metodologia para avaliar a eficiências dos gastos dos municípios do estado de São Paulo na área de saúde, permitindo, por meio de comparação, destacar os mais eficientes. Nele, os autores destacam que a metodologia apresentada pode resultar em avanços nos estudos sobre controladoria na gestão pública.

O presente estudo procurou sistematizar as pesquisas na área contábil durante o período de 2009 a 2014, nos periódicos de melhor estratificação da Capes - Qualis A. Porém, mesmo diante dos recortes metodológicos, entende-se que os principais periódicos utilizados na disseminação das pesquisas em contabilidade compuseram as análises. Entretanto, um aspecto limitador desta pesquisa, que pode ser levantado, é a utilização de palavras-chave para 
selecionar as publicações. Isto porque pode haver artigos abordando o tema pesquisado, mas que não utilizaram de maneira expressa as palavras-chave que foram empregadas. Outro limitador é quantidade de artigos analisados, vinte e oito no total, mesmo com o emprego de palavras-chave abrangentes.

\section{Referências}

American Accounting Association (AAA). A statement of basic accounting theory ASOBAT. Florida: American Accounting Association. 1996.

BERTOLUCCI, A.A.; IUDÍCIBUS, S. de. O futuro da pesquisa em contabilidade. In S. Iudícibus, \& A. B. Lopes (Org.) Teoria avançada da contabilidade. (pp. 276-300). São Paulo: Atlas. 2004.

BLAUG, M. Metodologia da economia. Tradução: Afonso Luiz Medeiros dos Santos Lima. (2a ed). São Paulo: Edusp.1993.

CAPES - Coordenação De Aperfeiçoamento De Pessoal De Nível Superior. Conheça a avaliação. Brasília. 2014.

CARDOSO, R. L.; MENDONÇA Neto, O. R. de; RICCIO, E. L.; SAKATA, M. C. G.. Pesquisa científica em contabilidade entre 1990 e 2003. Revista de Administração de Empresas, 45(2), pp. 34-45. 2005.

CARVALHO, M. C. M. de. K. R.. Popper: a falsificabilidade como critério de demarcação do discurso empírico-científico. In A. Oliva, (Org.). Epistemologia: a cientificidade em questão. (pp. 59-102). Campinas: Papirus. 1990.

COMITÊ DE PRONUNCIAMENTOS CONTÁBEIS (CPC). Estrutura conceitual para a elaboração e apresentação das demonstrações contábeis. Brasília. 2011.

FINANCIAL ACCOUNTING STANDARDS BOARD. (1978) Statement of financial accounting standards $\mathrm{n}^{\mathrm{o}} 1$. Objectives of Financial Reporting by Business Enterprises. Stamford, Connecticut.

FRANCELIN, M. M. Ciência, senso comum e revoluções científicas: ressonâncias e paradoxos. Ciência da Informação, 33(3), pp. 26-34. 2004.

FREZATTI, F., NASCIMENTO, A. R. do, e JUNQUEIRA, E. Desenvolvimento da pesquisa em Contabilidade Gerencial: as restrições da abordagem monoparadigmática de Zimmerman.

Revista Contabilidade \& Finanças, 20(49), pp. 6-24. 2009.

FREZATTI, F., RELVAS, T. R. S., e JUNQUEIRA, E. BSC e a estrutura de atributos da contabilidade gerencial: uma análise no ambiente brasileiro. Revista de Administração de Empresas, 50(2), pp. 187-198. 2010. 
GUERREIRO, R., CORNACCHIONE Jr, E. B., e SOUTES, D. O. Empresas que se destacam pela qualidade das informações a seus usuários externos também se destacam pela utilização de artefatos modernos de contabilidade gerencial? Revista Contabilidade \& Finanças, v.22(55), pp. 88-113. 2011.

MENDONÇA Neto; O. R., RICCIO, E. L.; SAKATA, M. C. G. Dez anos de pesquisa contábil no Brasil: análise dos trabalhos apresentados nos ENANPADS de 1996 a 2005. Revista de Administração de Empresas, 49(1), pp. 62-73. 2009.

MIRANDA, G. J.; CASA NOVA, S. P. de C.; CORNACCHIONE Jr, E. B. (2012). Os saberes dos professores-referência no ensino de contabilidade. Revista Contabilidade \& Finanças, 23(59), pp. 142-153. 2012.

NASCIMENTO, A. R. do; JUNQUEIRA, E.; MARTINS, G. de A. Pesquisa acadêmica em contabilidade gerencial no Brasil: análise e reflexões sobre teorias, metodologias e paradigmas. Revista de Administração Contemporânea, 14(6), pp. 1113-1133. 2010.

PATON, W. A. Accounting Theory: with special reference to the corporate enterprise. New York: The Ronald Press Company. 1922.

PETTERSON, M. H. et al. Manual de normas internacionais de contabilidade: IFRS versus normas brasileiras. (1a. ed). São Paulo: Atlas. 2009.

POPPER, K. A lógica da pesquisa científica. Tradução: Leonidas Hegenberg e Octanny Silveira da Mota. São Paulo: Edusp. 1975.

POPPER, K. Conjecturas e refutações: o desenvolvimento do conhecimento científico. Tradução de Benedita Bettencourt. Portugal, Coimbra: Editora Almedina. 2006.

REDMAN, D. A. Economics and the Philosophy of Science. New York, Oxford University Press. 1991.

THEÓPHILO, C. R.; IUDÍCIBUS, S. de. Uma Análise Crítico-Epistemológica da Produção Científica em Contabilidade no Brasil. Revista Contabilidade, Gestão e Governança, 8(2), pp. 147-175.

WASSERMAN, S.; FAUST, K. Social Network Analysis: Methods and Applications. New York: Cambridge Press. 1994. 